\title{
Effectiveness of peer teaching in medical education: medical student's perspective
}

This article was published in the following Dove Press journal:

Advances in Medical Education and Practice

\section{Farhiya Omar \\ Maryam Zaheer \\ Muna Ahmed}

Faculty of Medicine, St George's Hospital Medical School, London, UK
Correspondence: Farhiya Omar

Faculty of Medicine, St George's Hospital

Medical School, Cranmer Terrace,

London SWI7 ORE, UK

Tel +442054I5 3732

Email Farhiya.omar@hotmail.com

\section{Dear editor}

As three clinical-year medical students in the United Kingdom, we were particularly intrigued by Elhassan' ${ }^{1}$ research into a weekly educational activity called the "hospitalist huddle" in the United States. It explored the concept of peer teaching among doctors and its effectiveness. In this letter, we will discuss the usefulness of peer teaching for medical students as well as the different educational opportunities similar to the "hospitalist huddle" that exist in UK hospitals.

Peer teaching has been incorporated in many UK medical schools' curriculum to teach clinical skills and anatomy. It provides a safe and supportive educational environment for students, allows tutors to develop leadership and confidence, and alleviates pressures on faculties to find senior clinicians to teach. ${ }^{2}$ This concept of "flat hierarchies," which was explored by Elhassan, ${ }^{1}$ has been found to be an effective teaching tool. In fact, a study in Bahrain demonstrated that students taught by peers performed better in tutorials than those taught by faculty staff. ${ }^{3}$ Another form of peer teaching is near-peer teaching, where tutors are a few years more senior than tutees. A UK study showed that $97.9 \%$ of participants in a study found a near-peer teaching session to be a positive learning experience. ${ }^{4}$ However, as students who attend an institution with established peer tutor schemes, we are aware that peer teaching can sometimes result in a suboptimal learning experience. This is due to peer tutors being less knowledgeable than senior clinicians, which can risk incorrect information being taught. We commend the design of the "hospitalist huddle" as it ensured academic hospitalists were supervising all teams, thus reducing the chances of this occurring.

In UK hospitals, postgraduate peer teaching occurs through similar means as in the US. There are weekly journal clubs, grand rounds, and specialty-specific sessions, where doctors educate one another, as well as medical students, through case-based discussions. There is limited data regarding the effectiveness of these postgraduate teaching methods. However, Elhassan's ${ }^{1}$ research does suggest this is an effective method for postgraduate medical education, with $84 \%$ of respondents saying they were "very satisfied" or "satisfied" with the huddle as an educational experience. Having attended similar sessions as students, although at times cases are more complex than required for our understanding, it triggers interest and encourages us to do further reading. As well as clinical knowledge, these learning opportunities allow 
us to gain an insight into effective methods of teaching and delivering presentations. We have the opportunity to exercise these skills through participation in student grand rounds, which are very useful for our personal and professional development.

We believe that peer and near-peer teaching are both effective and valuable educational experiences for medical students, with much of the literature supporting this claim. However, quantitative data exploring the effectiveness of postgraduate peer teaching is limited; thus, we thank Elhassan for exploring this in such depth. We hope for the continued success of the "hospitalist huddle" and that peer teaching continues to thrive in medical education and clinical practice.

\section{Disclosure}

The authors report no conflicts of interest in this communication.

\section{References}

1. Elhassan M. The Hospitalist Huddle: a 1-year experience of teaching Hospital Medicine utilizing the concept of peer teaching in medical education. Adv Med Educ Pract. 2017;8:785-789.

2. Ten Cate O, Durning S. Peer teaching in medical education: twelve reasons to move from theory to practice. Med Teach. 2007;29(6):591-599.

3. Kassab S, Abu-Hijleh M, Al-Shboul Q, Hamdy H. Student-led tutorials in problem-based learning: educational outcomes and students' perceptions. Med Teach. 2005;27(6):521-526.

4. Rashid M, Sobowale O, Gore D. A near-peer teaching program designed, developed and delivered exclusively by recent medical graduates for final year medical students sitting the final objective structured clinical examination (OSCE). BMC Med Educ. 2011;11(1):11. 


\section{Author's reply \\ Mohammed Elhassan}

Department of Internal Medicine, Division of Hospital Medicine, UCSF/Fresno Center for Medical Education and Research, Fresno, CA, USA

Correspondence: Mohammed Elhassan

Department of Internal Medicine, Division of Hospital Medicine, UCSF/

Fresno Center for Medical Education and Research, 155 N Fresno St,

Fresno, CA 9370I, USA

Tel +l 5594996500

Fax + I 559499650 I

Email melhassan@fresno.ucsf.edu

\section{Dear editor}

I read with interest and joy the letter written by Omar, Zaheer, and Ahmed, all clinical-year medical students in the United Kingdom, regarding their experience with peer and near-peer teaching in their institution. It is a delight to learn that their experience with this medical education tool is positive and affirmative. This adds support to the notion that teaching with flat hierarchy is truly appealing for medial learners at different educational levels and within different clinical settings, not only in the US, but also in other similar medical education systems.

Regarding the "hospitalist huddle" in our institution, we do have medical students every now and then rotating with our residents for a couple of weeks as part of their clinical rotation. Informal feedback from them regarding their experience with the activity seems to be promising, but we do not have enough data to support that (yet!). I think it would be an excellent idea to examine this experience more closely and explore medical students' perspectives in more depth and detail to ensure satisfaction with the educational value of the huddle at all medical training levels, including medical students doing clinical rotations.

I also agree that some sort of supervision from more experienced learners (eg, chief residents) and/or clinicians would ensure optimization of the learning experience and at the same time can create good opportunities to provide constructive feedback to all participants during or after the activity. Nevertheless, the supervisor or facilitator needs to make sure that the safe and supportive environment that peer teaching creates is not clouded by their presence.

I look forward to hearing more about similar activities in other settings, and also read more about learners' perspectives when it comes to their learning experiences with peer and near-peer teaching.

\section{Disclosure}

The author reports no conflicts of interest in this communication.

Dove Medical Press encourages responsible, free and frank academic debate. The content of the Advances in Medical Education and Practice 'letters to the editor' section does not necessarily represent the views of Dove Medical Press, its officers, agents, employees, related entities or the Advances in Medical Education and Practice editors. While all reasonable steps have been taken to confirm the content of each letter, Dove Medical Press accepts no liability in respect of the content of any letter, nor is it responsible for the content and accuracy of any letter to the editor.

\section{Publish your work in this journal}

Advances in Medical Education and Practice is an international, peerreviewed, open access journal that aims to present and publish research on Medical Education covering medical, dental, nursing and allied health care professional education. The journal covers undergraduate education, postgraduate training and continuing medical education including emerging trends and innovative models linking education, research, and health care services. The manuscript management system is completely online and includes a very quick and fair peer-review system. Visit http://www.dovepress.com/testimonials.php to read real quotes from published authors. 